\title{
Participation as an outcome measure in psychosocial oncology: content of cancer-specific health-related quality of life instruments
}

\author{
Sijrike F. van der Mei • Marcel P. J. M. Dijkers • Yvonne F. Heerkens
}

Accepted: 23 March 2011/Published online: 10 April 2011

(C) The Author(s) 2011. This article is published with open access at Springerlink.com

\begin{abstract}
Purpose To examine to what extent the concept and the domains of participation as defined in the International Classification of Functioning, Disability and Health (ICF) are represented in general cancer-specific health-related quality of life (HRQOL) instruments.

Methods Using the ICF linking rules, two coders independently extracted the meaningful concepts of ten instruments and linked these to ICF codes.

Results The proportion of concepts that could be linked to ICF codes ranged from 68 to $95 \%$. Although all instruments contained concepts linked to Participation (Chapters d7-d9 of the classification of 'Activities and Participation'), the instruments covered only a small part of all available ICF codes. The proportion of ICF codes in the instruments that were participation related ranged from 3 to $35 \%$. 'Major life areas' (d8) was the most frequently used Participation Chapter, with d850 'remunerative employment' as the most used ICF code.
\end{abstract}

S. F. van der Mei $(\square)$

Department of Health Sciences, Graduate School for Health

Research SHARE, University Medical Center Groningen,

University of Groningen, PO Box 196, 9700 AD Groningen,

The Netherlands

e-mail: s.f.van.der.mei@med.umcg.nl

M. P. J. M. Dijkers

Department of Rehabilitation Medicine, Mount Sinai

School of Medicine, New York, NY, USA

Y. F. Heerkens

Faculty of Health and Social Studies, HAN University

of Applied Sciences, Nijmegen, The Netherlands

Y. F. Heerkens

Dutch Institute of Allied Health Care, Amersfoort,

The Netherlands
Conclusions The number of participation-related ICF codes covered in the instruments is limited. General cancer-specific HRQOL instruments only assess social life of cancer patients to a limited degree. This study's information on the content of these instruments may guide researchers in selecting the appropriate instrument for a specific research purpose.

Keywords Cancer - Psychosocial oncology · Participation · Quality of life · Questionnaires · Outcome assessment

$\begin{array}{ll}\text { Abbreviations } & \\ \text { ADLs } & \text { Activities of daily living } \\ \text { A\&P } & \text { Activities and Participation } \\ \text { BC } & \text { Breast cancer } \\ \text { CARES-SF } & \text { CAncer Rehabilitation Evaluation } \\ & \text { System-Short Form } \\ \text { CaSUN } & \text { Cancer Survivors' Unmet Needs } \\ & \text { measure } \\ \text { CI } & \text { Confidence interval } \\ \text { CPILS } & \text { Cancer Problems In Living Scale } \\ \text { EORTC-QLQ-C30 } & \text { European Organization for Research } \\ & \text { and Treatment of Cancer core } \\ & \text { Quality of Life Questionnaire } \\ \text { FACT-G } & \text { Functional Assessment of Cancer } \\ & \text { Therapy-General } \\ \text { FLIC } & \text { Functional Living Index-Cancer } \\ \text { HADS } & \text { Hospital Anxiety and Depression } \\ & \text { Scale } \\ \text { Hc } & \text { Health condition } \\ \text { HNC } & \text { Head and neck cancer } \\ \text { HRQOL } & \text { Health-related quality of life } \\ \text { ICF } & \text { International Classification of } \\ & \text { Functioning, disability and health } \\ & \end{array}$


IOCv2

$\mathrm{MC}$

$\mathrm{Nc}$

$\mathrm{Nd}$

$\mathrm{Nd}$-gh

Nd-mh

Nd-ph

Nd-qol

Pf

QLACS

QOL-CS

RSCL

SF-36

SLDS-C

SPSS

WHO
Impact Of Cancer version 2

Meaningful concept

Not covered

Not definable

Not definable-general health

Not definable-mental health

Not definable-physical health

Not definable-quality of life

Personal factors

Quality of Life in Adult Cancer

Survivor scale

Quality Of Life-Cancer Survivors

instrument

Rotterdam Symptom CheckList

Short-Form health survey

Satisfaction with Life Domains Scale

for Cancer

Statistical Package for the Social

Sciences

World Health Organization

\section{Introduction}

Many studies of cancer patients in past decades have focused on health-related quality of life (HRQOL), after the recognition of HRQOL as an important endpoint in cancer clinical research. Measurement instruments used in these studies generally focused on physical and psychological well-being, whereas the social dimension of HRQOL tended to be under-represented [1]. Given increased survival rates and the consequent rise in the number of patients with a history of cancer, as well as the burden of illness in cancer survivors [2], it seems that the social domain of HRQOL should be an area of greater interest. Moreover, it would be in line with the definition of health by the World Health Organization (WHO) that states that 'Health is a state of complete physical, mental and social well-being and not merely the absence of disease or infirmity' [3]. The International Classification of Functioning, Disability and Health (ICF), published by the WHO in 2001 [4], is a much-used framework in the field of rehabilitation research. The framework of the ICF, as well as the concept of participation which it introduced, may be useful in cancer outcome research that aims to assess the social health aspect of the WHO's definition of health.

The ICF is a classification of human functioning and disability and systematically categorizes health and healthrelated states as well as contextual factors that may impact those states [4]. It is applicable to all persons and not only to those with a disability. Disability encompasses the presence of impairments, activity limitations and participation restrictions, all of which may result from health conditions (disease, disorder and injury), and are impacted by personal factors as well as environmental factors. Participation, defined as 'involvement in a life situation' ([4], p. 10), is differentiated from activity, defined as 'the execution of a task or action'. The ICF offers a taxonomy for the domain of 'Activities and Participation' (A\&P) with nine Chapters that cover an extensive list of basic activities of daily living (ADLs), instrumental ADLs, and roles and activities generally studied as part of community integration, social health or social role participation.

Despite the potential value of the biopsychosocial framework of the ICF for the field of oncology research [57], to date this framework has been applied on a modest scale, and only a few empirical studies have explicitly used the ICF as a frame of reference [8-11]. One use of the ICF involved the development of Core Sets of cancer-specific symptoms and problems in functioning of cancer patients [12-14]. Furthermore, the ICF has served as a tool for the identification of concepts represented in outcome measures. Brockow et al. [15] analysed outcome measures used in clinical trials in breast cancer and concluded that functional aspects related to disability and participation were poorly addressed. Tschiesner et al. [16] examined HRQOL measures developed for head and neck cancer and found a large variation in the use of participation items. These results are in line with older literature that indicates that the social domain of HRQOL is under-represented in instruments $[1,17]$ and that the difficulties cancer patients experience in this area have had relatively limited attention in the field of psychosocial oncology [18].

Historically, in the field of oncology, HRQOL instruments have been used to give clinicians and policy makers systematic information about cancer patients' capacity or actual performance in important domains of life [19]. In the light of the WHO's definition of health, these instruments should adequately reflect all three dimensions of healthphysical, mental and social. Therefore, it is important to know whether participation, a construct that coincides with social functioning or social health, which also is an agreedupon key domain of HRQOL [20], is addressed in instruments that are widely used in cancer research.

This paper aims to examine to what extent the overall concept and the specific domains of participation as defined by the ICF are represented in well-known general cancerspecific HRQOL instruments used in psychosocial oncology research. Because of the specific focus on the content of existing instruments, a review of the quality (e.g. reliability and validity) of the instruments is beyond the scope of this paper. This paper gives insight as to which domains of participation are addressed by each of the instruments and will assist researchers in the selection of relevant measures. 


\section{Methods}

Selection of cancer-specific HRQOL instruments

HRQOL as an outcome in oncology can be measured using generic instruments, cancer-specific general instruments that can be used with patients with all types of cancers, and cancer site-specific instruments [21]. Our study aimed to include general cancer-specific HRQOL instruments, specifically developed for use in oncology research. To identify these instruments, we screened review papers and chapters published in English between 2000 and 2008 that aimed to give an overview of HRQOL instruments developed for adult cancer patients [19, 22-24]. This resulted in a broad range of instruments used in oncology research. In the light of the aim of our study, we excluded instruments that were: (1) generic instruments (e.g. SF-36 [25]); (2) cancer site-specific instruments (e.g. modular supplements of the EORTC-QLQ-C30 [26]); (3) domain-specific HRQOL instruments designed to assess one specific aspect of HRQOL (e.g. the Hospital Anxiety and Depression Scale (HADS) [27]); and (4) instruments that did not assess HRQOL but presumably another concept, such as unmet needs $[28,29]$.

\section{Content identification using the ICF linking rules}

The ICF provides a systematic coding scheme with alphanumeric codes at a maximum of four hierarchical levels of detail, for instance:

'd7 Interpersonal interactions and relationships' (first level)

'd750 Informal social relationships' (second level)

'd7500 Informal relationships with friends' (third level)

To link cancer-specific HRQOL instruments to the ICF codes, we used a methodology developed by Cieza et al. $[30,31]$, the ICF linking rules. These rules enable researchers to systematically link the items of outcome measures to the ICF and result in an inventory of concepts used within instruments. Following these linking rules, each meaningful concept (MC), i.e. unit of text that conveys a single theme [32] within an instrument item, is linked to the most appropriate corresponding ICF category, identified with its alphanumerical code that indicates the component of the ICF: body functions (b), body structures (s), A\&P (d) and environmental factors (e). For example, the item of the Short Form 12 [33] 'During the past week, how much did pain interfere with your normal work (including both work outside the home and housework)?' has been linked to the ICF categories b280 'sensation of pain', d850 'remunerative employment' and d640 'doing housework' [31]. As the ICF does not offer a taxonomy for personal factors, MCs of instrument items that fall within this component are only coded with 'Pf' [31].

In agreement with the linking rules [31], introductory sentences and instructions of the instruments under study were not linked. Response options of an item were only linked if they contained MCs. According to the linking rules, if MCs are explained by examples, both the concept and the examples are linked. If a MC does not provide sufficient information to make a decision about the most precise ICF category, the concept is not definable and is assigned the code 'Nd'. Not definable MCs that refer to health in general or a more specific aspect of health are assigned 'Nd-gh' (not definable-general health), 'Nd-ph' (not definable-physical health) or 'Nd-mh' (not definablemental health). MCs that refer to quality of life are assigned 'Nd-qol' (not definable-quality of life), and MCs that refer to a health condition are assigned ' $\mathrm{Hc}$ ' (health condition). Furthermore, if MCs are not represented in the ICF, they are assigned ' $\mathrm{Nc}$ ' (not covered by ICF).

Higher-level Chapter codes were assigned if MCs could not be assigned to a category lower in the hierarchy. Code 'b' (body functions) was assigned to items using nonspecific words such as 'side effects', 'symptoms' and '(changes in) body'. Code 'd' (A\&P) was assigned to items using nonspecific terms such as 'activities', 'things you want to do' and 'former roles'. Similarly, A\&P Chapter codes were assigned when a more precise second- or third-level code was not available: 'need to stay in bed or a chair during the day' (d4); 'not being able to care for myself' (d5); 'jobs around the house, activities at home' (d6); 'personal relationships' (d7); and 'social activities' (d9). Perceptions were not coded if they were inextricably bound up with other MCs (e.g. in 'feeling nervous' only 'nervous' was coded; in 'worry about illness' both worry and illness were coded).

Two coders (SFM and $\mathrm{YH}$ ) with knowledge of the contents of the ICF independently extracted MCs from the instrument items and linked these to ICF codes. The instruments were processed one at a time, and after each measure had been completed, the codes assigned were compared. Disagreement was defined as the identification of different MCs or the assignment of different ICF codes. Discussion of disagreement resulted in a consensus decision which ICF code to use. The reliability of this procedure was tested for three instruments that were linked in the last part of the linking procedure. The inter-coder agreement was quantified by calculating kappa with its $95 \%$ confidence interval (CI). Calculations were performed with the statistical software package SPSS, version 16.0 (SPSS Inc., Chicago IL., USA). 
Analyses of results of the linking procedure

In presenting the results of the linking procedure, the number of identified MCs, including the duplicates (i.e. MCs that are assigned more than once), in a particular instrument was determined. To examine how many MCs are contained in one item of the instrument, we computed the content density, defined as the ratio of the number of MCs divided by the number of items in an instrument [34]. If each item contains one $\mathrm{MC}$, then the content density equals 1.0; higher values express that more than one MC is found in the average item of the instrument. The content density represents an aspect of the content validity of instruments; the higher the content density, the more complex the item [35]. To examine the content diversity, we calculated the number of different ICF codes (irrespective of the level of detail) divided by the number of MCs [34]. The content diversity represents the number of MCs corresponding to one and the same ICF code. If each MC is linked to a different ICF code, then the content diversity equals 1.0; a value towards zero expresses that several MCs are linked to the same ICF code. A lower content diversity may indicate a more differentiated and specific measurement of the topics that an instrument aims to explore.

Furthermore, we summarized the number of MCs that could be linked to ICF codes as well as the MCs that could not be linked to ICF codes and accordingly were assigned 'Hc', 'Nd' and 'Nc' codes. To provide insight into the extent to which the components of the ICF are covered by cancer-specific HRQOL instruments, we determined the frequency distribution of the different ICF categories across the components of body functions, body structures, A\&P, environmental factors and personal factors. Within the component of A\&P, a distinction was made between Chapters covering Activities (d1 through d6) and Chapters covering Participation (d7 through d9), as recommended by Whiteneck and Dijkers [36]. This expedient approach was chosen because of the lack of agreement in the literature on how to distinguish the ICF A\&P taxonomy activities from participation [37-39] and the conflicting results of empirical studies on this issue [40-42].

For the interpretation of the linking results, we compare our findings with the ICF Core Sets developed for two cancer subgroups (i.e. breast cancer [12]; head and neck cancer [13]). There is no ICF Core Set for cancer in general. ICF Core Sets are a selection of categories out of the entire ICF classification that are relevant for a specific disease process [43]. A Comprehensive ICF Core Set allows multidisciplinary assessment of the typical spectrum of problems in functioning of patients, whereas a Brief ICF Core Set includes only the most important categories [44]. Our results were compared with the Comprehensive and the Brief cancer Core Sets.

\section{Results}

We identified ten general cancer-specific HRQOL instruments

1. Functional Living Index-Cancer (FLIC) [45];

2. Rotterdam Symptom CheckList (RSCL) [46];

3. CAncer Rehabilitation Evaluation System-Short Form (CARES-SF) [47];

4. Satisfaction with Life Domains Scale for Cancer (SLDS-C) [48];

5. European Organization for Research and Treatment of Cancer core Quality of Life Questionnaire (EORTCQLQ-C30; version 3) [26];

6. Functional Assessment of Cancer Therapy-General (FACT-G; version 4) [49];

7. Quality of Life-Cancers Survivors instrument (QOLCS) [50];

8. Cancer Problems in Living Scale (CPILS) [51];

9. Quality of Life in Adult Cancer Survivor scale (QLACS) [52, 53];

10. Impact of Cancer version 2 (IOCv2) [54, 55].

Analyses of the reliability of the linking procedure showed good results. The inter-coder agreement for the SLDS-C was $79 \%$ (kappa 0.81 ; 95\% CI 0.67-0.96). Inter-coder agreement for the CPILS and QOL-CS was 64 and $76 \%$, and kappa values were 0.65 (95\% CI 0.50-0.80) and 0.74 (95\% CI 0.65-0.84), respectively.

Table 1 summarizes the results of the linking procedure. The number of items in the instruments ranged from 18 to 59 , and the total number of identified MCs ranged from 23 to 150 . With a high number of MCs per item, the IOCv2 has the highest content density ratio (3.2), while the RSCL has the lowest content density ratio (1.1) with $42 \mathrm{MCs}$ assigned to 39 instrument items.

The proportion of MCs that could be linked to ICF codes ranged from $68 \%$ (IOCv2) to $95 \%$ (RSCL). MCs that were classified as 'not definable' mostly received the designation of 'general health'. The IOCv2 had the highest number of MCs that were linked to 'health condition' $(n=32)$. This scale often uses 'cancer' in its items (e.g. 'Having had cancer has made me feel alone'). MCs classified as 'not covered' (Nc) addressed items such as 'dying', 'future', 'time in life is running out', 'direction in life' and 'positive changes in life'. The number of different ICF codes assigned to the instruments ranged from 17 to 50 . With respect to content diversity, the QOL-CS had the lowest ratio (0.30); 79 MCs were linked to 24 different ICF codes. The SLDS-C and RSCL both had a content diversity ratio of 0.74 .

Table 2 shows the distribution of MCs in each of the ten instruments over the five major ICF components. All instruments contained concepts linked to A\&P. With the 


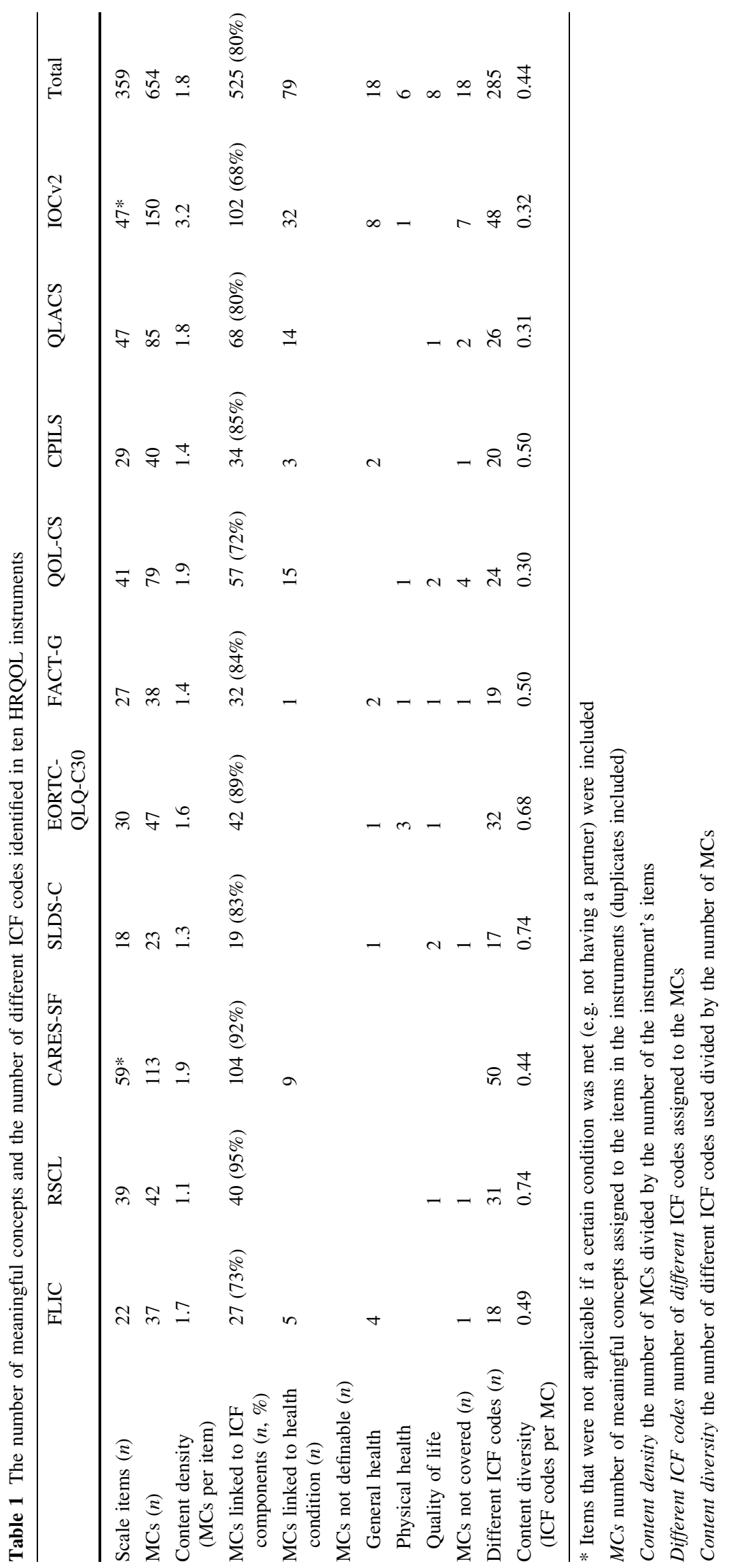


Table 2 Representation of the ICF components in ten HRQOL instruments

\begin{tabular}{|c|c|c|c|c|c|c|c|c|c|c|c|}
\hline & & FLIC & RSCL & CARES-SF & SLDS-C & $\begin{array}{l}\text { EORTC- } \\
\text { QLQ-C30 }\end{array}$ & FACT-G & QOL-CS & CPILS & QLACS & IOCv2 \\
\hline \multicolumn{2}{|c|}{ Different ICF codes $(n)$} & 18 & 31 & 50 & 17 & 32 & 19 & 24 & 20 & 26 & 48 \\
\hline \multicolumn{12}{|c|}{ ICF components* } \\
\hline $\mathrm{b}$ & Body functions & $28 \%$ & $74 \%$ & $32 \%$ & $29 \%$ & $38 \%$ & $37 \%$ & $58 \%$ & $50 \%$ & $46 \%$ & $35 \%$ \\
\hline $\mathrm{s}$ & Body structures & & & $2 \%$ & $6 \%$ & & & & & & \\
\hline \multirow[t]{3}{*}{ d } & Activities and Participation & & & & & & & & & & \\
\hline & Activities & $39 \%$ & $23 \%$ & $30 \%$ & $24 \%$ & $41 \%$ & $11 \%$ & $4 \%$ & $5 \%$ & $12 \%$ & $17 \%$ \\
\hline & Participation & $17 \%$ & $3 \%$ & $12 \%$ & $35 \%$ & $19 \%$ & $21 \%$ & $25 \%$ & $25 \%$ & $27 \%$ & $29 \%$ \\
\hline $\mathrm{e}$ & Environmental factors & $11 \%$ & & $22 \%$ & $6 \%$ & $3 \%$ & $26 \%$ & $8 \%$ & $15 \%$ & $12 \%$ & $17 \%$ \\
\hline pf & Personal factors & $6 \%$ & & $2 \%$ & & & $5 \%$ & $4 \%$ & $5 \%$ & $4 \%$ & $2 \%$ \\
\hline
\end{tabular}

* Column entries show the percentage of different ICF codes in each instrument that is linked to the ICF component listed Due to rounding, the sum of percentages can be less than or greater than $100 \%$

exception of the RSCL, all instruments addressed 'environmental factors' (range 3-26\%) and MCs classified as 'personal factors' were present in 7 scales (range 2-6\%). A substantial part of the MCs in each instrument is linked to the component 'body functions'.

The proportion of participation-related ICF codes ranged from 3 to $35 \%$. The SLDS-C has the highest proportion of such codes followed by the IOCv2. For four out of 10 instruments, less than $20 \%$ of MCs were linked to participation-related ICF codes. In the RSCL, only $3 \%$ of the instrument's MCs could be linked to participation.
Table 3 presents the distribution of MCs over the nine Chapters of A\&P. With respect to Participation, six of the instruments address all three Participation Chapters. Three instruments (i.e. FLIC, CARES-SF and CPILS) only address 2 Chapters, and the RSCL only 1. The FLIC and RSCL do not contain MCs related to 'Interpersonal interactions and relationships' (Chapter 7). Similarly, 'Community, social and civic life' (Chapter 9) is not covered by the RSCL, CARES-SF and CPILS. Chapter d8 'Major life areas' is the most used Participation Chapter and is covered by all instruments. With respect to all nine A\&P Chapters,

Table 3 Representation of the ICF Chapters 'Activities and Participation' in ten HRQOL instruments

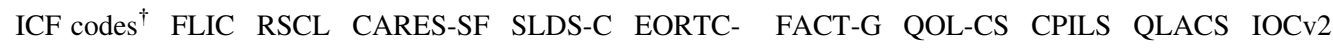
QLQ-C30

\begin{tabular}{|c|c|c|c|c|c|c|c|c|c|c|c|c|}
\hline \multicolumn{13}{|c|}{ Activities* } \\
\hline $\mathrm{d} 1$ & $\begin{array}{l}\text { Learning and applying } \\
\text { knowledge }\end{array}$ & 17 & $6 \%$ & & & & $18 \%$ & & & & $6 \%$ & $6 \%$ \\
\hline $\mathrm{d} 2$ & $\begin{array}{l}\text { General tasks } \\
\text { and demands }\end{array}$ & 5 & $40 \%$ & & & & $20 \%$ & & & & $20 \%$ & \\
\hline d3 & Communication & 12 & & & $17 \%$ & $17 \%$ & & & & & & $25 \%$ \\
\hline $\mathrm{d} 4$ & Mobility & 15 & & $13 \%$ & $20 \%$ & & $20 \%$ & $7 \%$ & & & & \\
\hline d5 & Self-care & 8 & & $25 \%$ & $63 \%$ & $13 \%$ & $50 \%$ & & & $13 \%$ & & $25 \%$ \\
\hline d6 & Domestic life & 7 & $57 \%$ & $29 \%$ & $29 \%$ & $14 \%$ & & $14 \%$ & $14 \%$ & & & $14 \%$ \\
\hline \multicolumn{13}{|c|}{ Participation* } \\
\hline d7 & $\begin{array}{l}\text { Interpersonal interactions } \\
\text { and relationships }\end{array}$ & 8 & & & $13 \%$ & $38 \%$ & $13 \%$ & $25 \%$ & $25 \%$ & $13 \%$ & $38 \%$ & $63 \%$ \\
\hline $\mathrm{d} 8$ & Major life areas & 13 & $8 \%$ & $8 \%$ & $23 \%$ & $15 \%$ & $15 \%$ & $8 \%$ & $15 \%$ & $15 \%$ & $8 \%$ & $31 \%$ \\
\hline d9 & $\begin{array}{l}\text { Community, social, } \\
\text { and civic life }\end{array}$ & 6 & $17 \%$ & & & $17 \%$ & $33 \%$ & $17 \%$ & $17 \%$ & & $33 \%$ & $17 \%$ \\
\hline
\end{tabular}

$\dagger$ Total number of first- and second-level ICF codes within each of the ICF A\&P Chapters listed; 'other specified' and 'unspecified' codes excluded

* Per cent of the ICF codes that is represented in the instrument, calculated per A\&P Chapter (number of first- and second-level ICF codes identified in the instrument divided by the total number of first- and second-level ICF codes in the corresponding A\&P Chapter; 'other specified' and 'unspecified' codes excluded) 
Table 4 ICF Chapters addressing Participation represented in ten HRQOL instruments, presented at the detail of the second-level of the ICF

\begin{tabular}{|c|c|c|c|c|c|c|c|c|c|c|c|c|c|c|}
\hline & & \multirow[t]{2}{*}{$\begin{array}{l}\text { ICF } \\
\text { codes* }\end{array}$} & \multirow[t]{2}{*}{ FLIC } & \multirow[t]{2}{*}{ RSCL } & \multirow[t]{2}{*}{$\begin{array}{l}\text { CARES- } \\
\text { SF }\end{array}$} & \multirow[t]{2}{*}{$\begin{array}{l}\text { SLDS- } \\
\mathrm{C}\end{array}$} & \multirow{2}{*}{$\begin{array}{l}\text { EORTC- } \\
\text { QLQ- } \\
\text { C30 }\end{array}$} & \multirow[t]{2}{*}{$\begin{array}{l}\text { FACT- } \\
\text { G }\end{array}$} & \multirow[t]{2}{*}{$\begin{array}{l}\text { QOL- } \\
\text { CS }\end{array}$} & \multirow[t]{2}{*}{ CPILS } & \multirow[t]{2}{*}{ QLACS } & \multirow[t]{2}{*}{ IOCv2 } & \multicolumn{2}{|c|}{$\begin{array}{l}\text { ICF Core } \\
\text { Sets }\end{array}$} \\
\hline & & & & & & & & & & & & & $\mathrm{HNC}$ & $\mathrm{BC}$ \\
\hline d7 & $\begin{array}{l}\text { Interpersonal } \\
\text { interactions } \\
\text { and relationships }\end{array}$ & 7 & & & & & & & & & & & & \\
\hline d710 & $\begin{array}{l}\text { Basic interpersonal } \\
\text { interactions }\end{array}$ & & & & & & & & & & & + & $\mathbf{\square}$ & \\
\hline d720 & $\begin{array}{l}\text { Complex } \\
\text { interpersonal } \\
\text { interactions }\end{array}$ & & & & & & & & & & + & $+[+]$ & $\mathbf{\square}$ & $\mathbf{\square}$ \\
\hline d750 & $\begin{array}{l}\text { Informal social } \\
\text { relationships }\end{array}$ & & & & & + & & & & & + & + & $\mathbf{\square}$ & $\mathbf{\square}$ \\
\hline d760 & Family relationships & & & & & + & + & + & & + & & {$[+]$} & $\mathbf{\square} \square$ & \\
\hline $\mathrm{d} 770$ & Intimate relationships & & & & + & + & & + & + & & + & $+[+]$ & $\mathbf{\square}$ & $\mathbf{\square}$ \\
\hline d8 & Major life areas & 12 & & & & & & & & & & & & \\
\hline $\mathrm{d} 845$ & $\begin{array}{l}\text { Acquiring, keeping } \\
\text { and terminating } \\
\text { a job }\end{array}$ & & & & + & & & & & + & & + & $\mathbf{\square}$ & \\
\hline $\mathrm{d} 850$ & $\begin{array}{l}\text { Remunerative } \\
\text { employment }\end{array}$ & & + & + & + & + & + & + & + & & & $+[+]$ & & \\
\hline $\mathrm{d} 870$ & $\begin{array}{l}\text { Economic self- } \\
\text { sufficiency }\end{array}$ & & & & + & & + & & + & + & + & & $\mathbf{\square} \square$ & \\
\hline d9 & $\begin{array}{l}\text { Community, social } \\
\text { and civic life }\end{array}$ & 5 & & & & & & & & & & & & \\
\hline d910 & Community life & & & & & & & & & & & & $\mathbf{\square}$ & \\
\hline d920 & $\begin{array}{l}\text { Recreation and } \\
\text { leisure }\end{array}$ & & + & & & + & + & + & & & + & {$[+]$} & $\mathbf{\square}$ & $\mathbf{\square}$ \\
\hline d930 & $\begin{array}{c}\text { Religion and } \\
\text { spirituality }\end{array}$ & & & & & & & & + & & & & $\mathbf{\square}$ & \\
\hline
\end{tabular}

* Total number of second-level ICF codes in each Participation Chapter ('other specified' and 'unspecified' codes excluded)

ICF codes not covered in the instruments or in the ICF Core Sets are omitted from this table

+ indicates that the ICF code is represented in the instrument

$[+]$ indicates that the ICF code is represented in the instrument as an example

indicates that the ICF code is represented in the Comprehensive ICF Core Sets for head and neck cancer (HNC) or breast cancer (BC)

$\square$ indicates that the ICF code is represented in the Brief ICF Core Sets for HNC or BC

the EORTC-QLQ-C30 and the IOCv2 cover the most (7 out of 9), whereas the CPILS covers only 3 Chapters.

Table 4 presents the second-level ICF codes of the Participation Chapters (Chapters 7-9) that were identified in the instruments. Certain ICF participation codes were not covered at all (omitted from the table): d730 'relating with strangers', d740 'formal relationships' (e.g. relationship with employer), d810 through d830 'education', d840 'apprenticeship (work preparation)', d855 'non-remunerative employment', d860 'basic economic transactions', b865 'complex economic transactions', d910 'community life' (e.g. engagement in social clubs and associations), d940 'human rights' and d950 'political life and citizenship'. Although the SLDS-C and IOCv2 contain the MC 'school', due to the lack of specificity on the type of education this concept was linked to the code $\mathrm{d} 8$ ("Major life areas') and not more specifically to one of the thirdlevel education codes.

The most frequently used ICF code is d850 'remunerative employment'; only the CPILS and the QLACS do not have MCs corresponding to this code (Table 4). Other frequently used ICF codes were $\mathrm{d} 770$ 'intimate relationships' and d920 'recreation and leisure', both covered in $60 \%$ of the instruments. d760 'family relationships' and $\mathrm{d} 870$ 'economic self-sufficiency' were covered in half of the instruments. A minority of the scales included 'complex interpersonal interactions' (d720) and 'informal social relationships' (d750), as well as 'acquiring, keeping and terminating a job' (d845). The ICF category 'religion and spirituality' (d930) was covered by just one scale. 
The section 'work and employment' (d840-d859) of Chapter 8 'Major life areas' contains the most frequently used ICF code d850 ('remunerative employment'). The MCs linked to this code differ in the wording used such as employment (QOL-CS), job (SLDS-C), go to work (RSCL), ability to work (CARES-SF) and not being able to work (IOCv2). In addition, the aspect of interest related to work that is asked about differs between instruments (e.g. ability, limitation, satisfaction and fulfilment).

Comparison of assigned participation-related ICF codes with the ICF Core Sets (Table 4) showed that none of the HRQOL instruments covers the entire Comprehensive ICF Core Set for head and neck cancer (HNC), whereas the comprehensive set for breast cancer (BC) is only covered by the IOCv2. The Brief Core Set for HNC is covered by the EORTC-QLQ-C30 and the CPILS. The Brief Core Set for BC is covered by the SLDS-C, FACT-G and IOCv2.

\section{Discussion}

This study provides an overview of the content of general cancer-specific HRQOL instruments. Content identification was performed by linking meaningful concepts in instrument items to the ICF domains by applying the ICF linking rules. All ten instruments selected contain concepts that represent participation as defined by the ICF (Chapters $\mathrm{d} 7$ through d9 of the classification of Activities and Participation). However, the number of ICF participation codes covered in the instruments is limited. Aside from the total absence of some ICF codes across the ten scales, each instrument only contains a small part of all available ICF codes. With regard to interpersonal interactions and relationships (Chapter 7), the scales mainly assess intimate and family relationships, whereas formal and informal social relationships are minimally included. Work or employment is covered by all scales, but other areas listed in Chapter 8, such as getting an education, are under-represented. Nonremunerative employment (volunteering) is not covered by any of the instruments. The least adequately covered is Chapter 9 'Community, social and civic life' with areas such as engagement in social life outside the family, participation in religion and spirituality, human rights, political life and citizenship. These results indicate that the available general cancer-specific HRQOL instruments do not comprehensively assess participation in society by cancer patients.

Besides differences between measures in the domains of participation covered, the linkage procedure also showed differences in how many concepts and ICF codes are included per average item. There is variation in the number of MCs per item (content density), in the percentage of the MCs that could be linked to the ICF and in the diversity of the ICF codes covered. From a measurement methodology point of view, it is desirable that items are clearly stated with a minimum number of MCs. A high content density score indicates more complex items (more MCs per item). Patients may have difficulty understanding and answering these items. One may question how responses of patients to these 'dense' items should be interpreted. A low content diversity score indicates that several MCs relate to the same ICF code and may indicate redundancy of items. However, a low content diversity also facilitates a more differentiated and specific measurement. Content density and diversity may be helpful in comparing instruments and are useful indicators of the ICF-based contents of instruments [35].

The results show that participation is covered to a limited extent in well-known general cancer-specific HRQOL instruments. Whether this should be considered as a problem depends on the purpose of the researcher who uses these instruments. If the aim of a study is to present an overview of the effects of cancer or its treatment on patients' functioning, then some of the instruments are rather comprehensive. The EORTC-QLQ-C30 and IOCv2, for example, both cover seven of the nine A\&P Chapters and assess body functions as well. However, if the limited set of items in these instruments is used to draw firm conclusions regarding, for example, the social domain of HRQOL, there may be a problem because the extent to which the items are representative of a cancer patients' entire social life is limited.

It is debatable whether all ICF codes related to participation should be incorporated in new instruments that aim to comprehensively capture participation in society of cancer patients. Not all codes are equally important. The ICF Core Sets for HNC [13] and BC [12] do not include all participation-related ICF codes and even do not cover all three Participation Chapters. The choice as to which codes should be included in a measure may depend on the viewpoints and values of patients, if items are generated inductively, but may also be guided by the personal values and professional background of developers. The ICF Core Sets were developed by expert panels that for a major part consisted of physicians, which may have influenced the selection of ICF categories. Becker et al. [14] showed that a major part of the ICF codes linked by psychologists could be assigned to Chapter 1 'mental functions' of the ICF component 'body functions'. Becker's study also identified a participation-related code (i.e. d740 formal relationships) that was not included in the ICF Core Set for HNC developed by the expert panels. Clearly, the ICF Core Sets need further content validation, which is an ongoing process [56].

It was not the aim of this study to select a preferred measure. The instruments included in this review have all 
been developed for a specific purpose. Some are to be used during cancer treatment (e.g. EORTC-QLQ-C30), whereas others focus specifically on long-term survivorship (e.g. IOCv2). The choice of an instrument should be guided by the aim of the study and the research questions at stake. However, the results presented in Tables 1, 2, 3 and 4 may be used in selecting an appropriate instrument and therefore provide information that is of interest to both clinicians and researchers.

The application of the linking procedure to general cancer-specific HRQOL instruments provided some interesting results. Our study showed that seven of the ten instruments contain concepts that are coded as personal factors (e.g. coping, control, appreciation of life and feeling stigmatized), which are relevant to cancer patients. The ICF does not yet have a classification of personal factors; one certainly would be useful into psychosocial oncology. Also interesting is that while the majority of the instruments reviewed was developed before the publication of the ICF, the identification of a variety of domains of the ICF (e.g. body functions, limitations in activities, restrictions in participation, environmental and personal factors) indicates that their creators were cognizant of the multidimensional structure of and multifactorial causation of HRQOL.

The present study has some limitations. We only included instruments that are specific to any type of cancer. As a consequence, some instruments that have been of value in psychosocial oncology research were not included. We excluded, for example, a domain-specific HRQOL instrument such as the Social Difficulties Index [57]. Although the linking procedure was performed by experienced coders who followed Cieza's linking rules, the identification of MCs and the linking to ICF codes is a somewhat subjective process, as indicated by the less than perfect kappa statistics. For some items, it was unclear what the developer of the measure had in mind in wording the item. To distinguish Participation from Activities, we labelled Chapter 7, 8 and 9 as Chapters covering Participation [36], which is one out of 4 possible strategies listed in the ICF manual. This choice, which excludes domestic life as a domain of participation, may have influenced the findings of the study. We believe that the results are valuable despite these limitations and give insight into the shortcomings that cancer-specific HRQOL instruments have in measuring participation in society. To our knowledge, our study is the first that applies the linking procedure to general cancer-specific HRQOL instruments; it has shown that the linking procedure of Cieza et al. $[30,31]$ is useful in this area of research.

To conclude, even though general cancer-specific HRQOL instruments contain concepts that reflect participation in society as defined by the ICF, these concepts represent only a limited set of the available ICF codes.
Although the instruments may be useful to obtain an overview of various aspects of HRQOL, including the social domain, they do not result in a comprehensive assessment of participation in society. Researchers should be reticent in formulating conclusions on social outcomes of cancer and cancer treatment based on these instruments, because their items assess the social life of cancer patients to only a limited degree.

Acknowledgements The authors thank Wolfgang Viechtbauer, statistician in the Department of Methodology and Statistics of Maastricht University, and Bart Staal of the Scientific Institute for Quality of Healthcare of the Radboud University Nijmegen Medical Center for their statistical support. S.F. van der Mei was supported by a Fellowship from the Dutch Cancer Society. Grants H133N060027, H133B040033 and H133A070033 from the National Institute on Disability and Rehabilitation Research, Office of Special Education and Rehabilitative Services, U.S. Department of Education, supported M.P.J.M. Dijkers.

Open Access This article is distributed under the terms of the Creative Commons Attribution Noncommercial License which permits any noncommercial use, distribution, and reproduction in any medium, provided the original author(s) and source are credited.

\section{References}

1. Cella, D. (1998). Quality of life. In J. C. Holland (Ed.), Psychooncology (pp. 1135-1146). New York: Oxford University Press.

2. Yabroff, K. R., Lawrence, W. F., Clauser, S., Davis, W. W., \& Brown, M. L. (2004). Burden of illness in cancer survivors: Findings from a population-based national sample. Journal of the National Cancer Institute, 96(17), 1322-1330.

3. World Health Organization. (1948). Preamble to the constitution of the world health organization as adopted by the international health conference, New York, 19-22 June, 1946; signed on 22 July 1946 by the representatives of 61 States (Official records of the world health organization, no. 2, p. 100) and entered into force on 7 April 1948. http://www.who.int/about/definition/ en/print.html. Accessed 17 March 2011.

4. World Health Organization. (2001). International Classification of Functioning, Disability and Health. Geneva: WHO.

5. Eadie, T. L. (2003). The ICF: A proposed framework for comprehensive rehabilitation of individuals who use alaryngeal speech. American Journal of Speech-Language Pathology, 12(2), 189-197.

6. Parsons, J. A., \& Davis, A. M. (2004). Rehabilitation and qualityof-life issues in patients with extremity soft tissue sarcoma. Current Treatment Options in Oncology, 5(6), 477-488.

7. Gilchrist, L. S., Galantino, M. L., Wampler, M., Marchese, V. G., Morris, G. S., \& Ness, K. K. (2009). A framework for assessment in oncology rehabilitation. Physical Therapy, 89(3), 286-306.

8. Tschiesner, U., Linseisen, E., Coenen, M., Rogers, S., Harreus, U., Berghaus, A., et al. (2009). Evaluating sequelae after head and neck cancer from the patient perspective with the help of the International Classification of Functioning, Disability and Health. European Archives of Otorhinolaryngology, 266(3), 425-436.

9. Tschiesner, U., Linseisen, E., Baumann, S., Siedek, V., Stelter, K., Berghaus, A., et al. (2009). Assessment of functioning in patients with head and neck cancer according to the International Classification of Functioning, Disability and Health (ICF): A multicenter study. Laryngoscope, 119(5), 915-923. 
10. Mueller, M., Lohmann, S., Thul, P., Weimann, A., \& Grill, E. (2010). Functioning and health in patients with cancer on homeparenteral nutrition: A qualitative study. Health and Quality of Life Outcomes, 8(1), 41.

11. Tsauo, J. Y., Hung, H. C., Tsai, H. J., \& Huang, C. S. (2010). Can ICF model for patients with breast-cancer-related lymphedema predict quality of life? Supportive Care in Cancer. doi: 10.1007/ s00520-010-0857-2.

12. Brach, M., Cieza, A., Stucki, G., Fussl, M., Cole, A., Ellerin, B., et al. (2004). ICF core sets for breast cancer. Journal of Rehabilitation Medicine, 44(44 Suppl), S121-S127.

13. Tschiesner, U., Rogers, S., Dietz, A., Yueh, B., \& Cieza, A. (2010). Development of ICF core sets for head and neck cancer. Head and Neck, 32(2), 210-220.

14. Becker, S., Kirchberger, I., Cieza, A., Berghaus, A., Harreus, U., Reichel, O., et al. (2010). Content validation of the comprehensive ICF core set for head and neck cancer (HNC): The perspective of psychologists. Psychooncology, 19(6), 594-605.

15. Brockow, T., Duddeck, K., Geyh, S., Schwarzkopf, S., Weigl, M., Franke, T., et al. (2004). Identifying the concepts contained in outcome measures of clinical trials on breast cancer using the International Classification of Functioning, Disability and Health as a reference. Journal of Rehabilitation Medicine, 44(44 Suppl), S43-S48.

16. Tschiesner, U., Rogers, S., Harreus, U., Berghaus, A., \& Cieza, A. (2008). Content comparison of quality of life questionnaires used in head and neck cancer based on the International Classification of Functioning, Disability and Health: A systematic review. European Archives of Otorhinolaryngology, 265(6), 627-637.

17. De Haes, J. C., \& van Knippenberg, F. C. (1985). The quality of life of cancer patients: A review of the literature. Social Science and Medicine, 20(8), 809-817.

18. Wright, E. P., Kiely, M. A., Lynch, P., Cull, A., \& Selby, P. J. (2002). Social problems in oncology. British Journal of Cancer, 87(10), 1099-1104.

19. Erickson, P. (2005). Assessing health status and quality of cancer patients: The use of general instruments. In J. Lipscomb, C. C. Gotay, \& C. Snyder (Eds.), Outcomes assessment in cancer: Measures, methods and applications (pp. 31-68). Cambridge: Cambridge University Press.

20. WHOQOL. (1995). The world health organization quality of life assessment (WHOQOL): Position paper from the World Health Organization. Social Science and Medicine, 41(10), 1403-1409.

21. Soni, M. K., \& Cella, D. (2002). Quality of life and symptom measures in oncology: An overview. The American Journal of Managed Care, 8(18 Suppl), S560-S573.

22. Sprangers, M. A. (2002). Quality-of-life assessment in oncology. Achievements and challenges. Acta Oncologica, 41(3), 229-237.

23. Zebrack, B., \& Cella, D. (2005). Evaluating quality of life in cancer survivors. In J. Lipscomb, C. C. Gotay, \& C. Snyder (Eds.), Outcomes assessment in cancer: Measures, methods, and applications (pp. 241-263). Cambridge: Cambridge University Press.

24. Pearce, N. J., Sanson-Fisher, R., \& Campbell, H. S. (2008). Measuring quality of life in cancer survivors: A methodological review of existing scales. Psychooncology, 17(7), 629-640.

25. Ware, E. J., Jr, \& Sherbourne, C. D. (1992). The MOS 36-item short-form health survey (SF-36). I. Conceptual framework and item selection. Medical Care, 30(6), 473-483.

26. Aaronson, N. K., Ahmedzai, S., Bergman, B., Bullinger, M., Cull, A., Duez, N. J., et al. (1993). The european organization for research and treatment of cancer QLQ-C30: A quality-of-life instrument for use in international clinical trials in oncology. Journal of the National Cancer Institute, 85(5), 365-376.

27. Zigmond, A. S., \& Snaith, R. P. (1983). The hospital anxiety and depression scale. Acta Psychiatrica Scandinavica, 67(6), 361-370.
28. Thewes, B., Butow, P., Girgis, A., \& Pendlebury, S. (2004). Assessment of unmet needs among survivors of breast cancer. Journal of Psychosocial Oncology, 22(1), 51-73.

29. Hodgkinson, K., Butow, P., Hunt, G. E., Pendlebury, S., Hobbs, K. M., Lo, S. K., et al. (2007). The development and evaluation of a measure to assess cancer survivors' unmet supportive care needs: The CaSUN (Cancer Survivors' Unmet Needs measure). Psychooncology, 16(9), 796-804.

30. Cieza, A., Brockow, T., Ewert, T., Amman, E., Kollerits, B., Chatterji, S., et al. (2002). Linking health-status measurements to the International Classification of Functioning, Disability and Health. Journal of Rehabilitation Medicine, 34(5), 205-210.

31. Cieza, A., Geyh, S., Chatterji, S., Kostanjsek, N., Ustun, B., \& Stucki, G. (2005). ICF linking rules: An update based on lessons learned. Journal of Rehabilitation Medicine, 37(4), 212-218.

32. Escorpizo, R., Cieza, A., Beaton, D., \& Boonen, A. (2009). Content comparison of worker productivity questionnaires in arthritis and musculoskeletal conditions using the International Classification of Functioning, Disability and Health framework. Journal of Occupational Rehabilitation, 19(4), 382-397.

33. Ware, E. J., Jr, Kosinski, M., \& Keller, S. D. (1996). A 12-item short-form health survey: Construction of scales and preliminary tests of reliability and validity. Medical Care, 34(3), 220-233.

34. Geyh, S., Cieza, A., Kollerits, B., Grimby, G., \& Stucki, G. (2007). Content comparison of health-related quality of life measures used in stroke based on the International Classification of Functioning, Disability and Health (ICF): A systematic review. Quality of Life Research, 16(5), 833-851.

35. Gradinger, F., Glassel, A., Bentley, A., \& Stucki, A. (2011). Content comparison of 115 health status measures in sleep medicine using the International Classification of Functioning, Disability and Health (ICF) as a reference. Sleep Medicine Reviews, 15(1), 33-40.

36. Whiteneck, G., \& Dijkers, M. P. (2009). Difficult to measure constructs: Conceptual and methodological issues concerning participation and environmental factors. Archives of Physical Medicine and Rehabilitation, 90(11 Suppl), S22-S35.

37. Schuntermann, M. F. (2005). The implementation of the International Classification of Functioning, Disability and Health in Germany: Experiences and problems. International Journal of Rehabilitation Research, 28(2), 93-102.

38. Badley, E. M. (2008). Enhancing the conceptual clarity of the activity and participation components of the International Classification of Functioning, Disability and Health. Social Science and Medicine, 66(11), 2335-2345.

39. Dijkers, M. P. (2010). Issues in the conceptualization and measurement of participation: An overview. Archives of Physical Medicine and Rehabilitation, 91(9 Suppl), S5-S16.

40. Jette, A. M., Haley, S. M., \& Kooyoomjian, J. T. (2003). Are the ICF activity and participation dimensions distinct? Journal of Rehabilitation Medicine, 35(3), 145-149.

41. Jette, A. M., Tao, W., \& Haley, S. M. (2007). Blending activity and participation sub-domains of the ICF. Disability and Rehabilitation, 29(22), 1742-1750.

42. Post, M. W., de Witte, L. P., Reichrath, E., Verdonschot, M. M., Wijlhuizen, G. J., \& Perenboom, R. J. (2009). Development and validation of IMPACT-S, an ICF-based questionnaire to measure activities and participation. Journal of Rehabilitation Medicine, 40(8), 620-627.

43. Stucki, G., Cieza, A., Ewert, T., Kostanjsek, N., Chatterji, S., \& Ustun, T. B. (2002). Application of the International Classification of Functioning, Disability and Health (ICF) in clinical practice. Disability and Rehabilitation, 24(5), 281-282.

44. Cieza, A., Ewert, T., Ustun, T. B., Chatterji, S., Kostanjsek, N., \& Stucki, G. (2004). Development of ICF Core Sets for patients 
with chronic conditions. Journal of Rehabilitation Medicine, 36(44 Suppl), 9-11.

45. Schipper, H., Clinch, J., McMurray, A., \& Levitt, M. (1984). Measuring the quality of life of cancer patients: The functional living index-cancer: Development and validation. Journal of Clinical Oncology, 2(5), 472-483.

46. De Haes, J. C., van Knippenberg, F. C., \& Neijt, J. P. (1990). Measuring psychological and physical distress in cancer patients: Structure and application of the Rotterdam symptom checklist. British Journal of Cancer, 62(6), 1034-1038.

47. Schag, C. A., Ganz, P. A., \& Heinrich, R. L. (1991). Cancer rehabilitation evaluation system-short form (CARES-SF). A cancer specific rehabilitation and quality of life instrument. Cancer, 68(6), 1406-1413.

48. Baker, F., Curbow, B., \& Wingard, J. R. (1992). Development of the satisfaction with life domains scale for cancer. Journal of Psychosocial Oncology, 10(3), 75-90.

49. Cella, D. F., Tulsky, D. S., Gray, G., Sarafian, B., Linn, E., Bonomi, A., et al. (1993). The functional assessment of cancer therapy scale: Development and validation of the general measure. Journal of Clinical Oncology, 11(3), 570-579.

50. Ferrell, B. R., Dow, K. H., \& Grant, M. (1995). Measurement of the quality of life in cancer survivors. Quality of Life Research, 4(6), 523-531.

51. Baker, F., Denniston, M., Zabora, J. R., \& Marcellus, D. (2003). Cancer problems in living and quality of life after bone marrow transplantation. Journal of Clinical Psychology in Medical Settings, 10(1), 27-34.
52. Avis, N. E., Smith, K. W., McGraw, S., Smith, R. G., Petronis, V. M., \& Carver, C. S. (2005). Assessing quality of life in adult cancer survivors (QLACS). Quality of Life Research, 14(4), 1007-1023.

53. Avis, N. E., Ip, E., \& Foley, K. L. (2006). Evaluation of the quality of life in adult cancer survivors (QLACS) scale for longterm cancer survivors in a sample of breast cancer survivors. Health and Quality of Life Outcomes, 4, 92.

54. Zebrack, B. J., Ganz, P. A., Bernaards, C. A., Petersen, L., \& Abraham, L. (2006). Assessing the impact of cancer: Development of a new instrument for long-term survivors. Psychooncology, 15(5), 407-421.

55. Crespi, C. M., Ganz, P. A., Petersen, L., Castillo, A., \& Caan, B. (2008). Refinement and psychometric evaluation of the impact of cancer scale. Journal of the National Cancer Institute, 100(21), $1530-1541$.

56. Tschiesner, U., Linseisen, E., Becker, S., Mast, G., Rogers, S. N., Walvekar, R. R., et al. (2010). Content validation of the International Classification of Functioning, Disability and Health core sets for head and neck cancer: A multicentre study. Journal of Otolaryngology-Head and Neck Surgery, 39(6), 674-687.

57. Wright, E. P., Kiely, M., Johnston, C., Smith, A. B., Cull, A., \& Selby, P. J. (2005). Development and evaluation of an instrument to assess social difficulties in routine oncology practice. Quality of Life Research, 14(2), 373-386. 